\title{
Material selection of natural fibers for composite automotive component using analytic hierarchy process/analytic network process in concurrent engineering approach
}

\begin{abstract}
Material selection of natural fiber for composite based products is an essential process in product design development especially in application of automotive components. Several factors need to be considered concurrently and dependency among the factors should be evaluated during the judgement. Therefore, a proposed approach is presented in this study by using Analytic Hierarchy Process/Analytic Network Process (AHP/ANP) to prioritize the criteria for material selection of natural fiber composites automotive components. AHP computes the priority values from pairwise comparison basis and ANP derives the global priority values based on the inner dependency of the criteria. As in a case study, flax fibers obtained the highest value (19\%) and rank as number one fibers in the selection where tensile strength is the most significant criteria. Thus, application of AHP/ANP would derive a more reliable and accurate judgement in material selection and their flexibility allows integration with other decision making tools.
\end{abstract}

Keyword: Analytic hierarchy process; Analytic network process; Concurrent engineering; Material selection; Natural fiber composites 